have fully published from week to week. It is evident that the early diagnosis in general practice of plague is of national importance, and as we all learn far more from a mistaken than from a correct diagnosis I venture to supplement the report of one of the cases mentioned in Dr. A. K. Chalmers's valuable weekly report and at the same time to bring out two interesting facts from a practitioner's point of view. He refers to this case in this week's report as "Rosina M., unmarried, aged 25, of 23, Florence-street, sickened on August 23rd, and her illness was not recognised till Sept. 10th. She had no regular medical attendance."

I was called in to see this patient for the first time on Sept. 10 $\mathrm{th}$, and having seen the first cases, the Malloy cases, as well as the other cases at present in Belvidere Hospital, I had no difficulty in diagnosing bubonic plague, for in answer to my question: What is the matter with you? she at once directed $\mathrm{my}$ attention to very palpable, painful buboes in each groin. Moreover, she worked beside the other young women who had been to the "wake" in Rose-street and are now in Belvidere Hospital with plague. I learned from her mother that during her illness of 18 days she had been seen twice by a medical man. His first visit was when she sickened and was "raving," and his second visit was 14 days later. On calling on him he informed me that on his first visit her temperature was $104^{\circ} \mathrm{F}$., but on his second visit it was normal. He thought, not unreasonably, tbat the buboes were most probably gonorrhœal. I may add that when I saw her on Sept. 10th her temperature was normal, there was no rash or mottling of the skin, nor was there anything apparently the matter with her but the painful buboes in each groin. Now the two points I wish to emphasise are (1) that unless seen early the temperature, which would be a valuable differentiation sign between plague buboes and gonorrhoeal buboes, would be absent; and (2) that in my limited experience in cases where I suspected gonorrhœa in women 1 have never seen buboes although I often see them in men. I think that the common sequel of gonorrhcea in women is not a bubo but inflammation and suppuration of the valvo-vaginal or Bartholin's glands. If buboes are a rare sequela of gonorrhoa in women-and an authoritative statement at present on this point might be important-the fact of finding buboes in a woman, even with a history of suspected gonorrhoea, and especially with a rise of temperature, ought at the present time strongly to suggest bubonic plague. I am, Sirs, yours faithfully

Glasgow, Sept. 29th, 1900 THOMAS COLVIN.

\section{"INOCULATION AGAINST TYPHOID FEVER."}

To the Editors of THE LANCBT.

SIRS, - On seeing the leading article on this subject in THE LANCET of Sept. 29th (p. 952), I again studied the official report referred to, but must confess that I can see no reason to modify my criticism of it in the Times of Sept. 24th. Paragraph 3 of the report seems quite explicit, and the inoculation was certainly put a stop to at one time. Here is the passage :-

and it appears to have been understood from the concluding portion of the War Office letter of $24 \mathrm{th}$ January, 1898, that the prtion of objectlon of lord lansdowne to the introduction of the treatment applied rather to the public expense than to voluntary operations at privale cost. Under this supposition the latler have certain stations (advantage being taken of the presence of Professor Wright in this country as a me on the fact beconing turther inoculations, and the treatment has accordingly been abandoned.

The italics are mine. We have a perfectly clear statement, not only that the "inoculation at the public expense" was prohibited, but that when it became known that Professor Wright, then in India on the Plague Commission, was carrying on "voluntary operations at private cost," these, too, were put a stop to. If this is not "express prohibition" of inoculation against typhoid I do not know what is-at all events it seems to have effectually stopped it for a considerable period. That inoculation was resumed after August, 1899, has nothing to do with the question raised by me. I ask why it was that the measure was checked in 1898. I submit that though Government might reasonably have refused to encourage "inoculation at the public expense"though even this was in my own humble opinion thoroughly bad policy-yet they had no justification for going so far as to stop Dr. Wright's private inoculations altogether. In doing so they practically took up the position that the inoculation is harmful-that their own leading pathologist was going about poisoning their soldiers. If they did not think so, why did they prohibit the measure?

I am, Sirs, yours faithfully,

Liverpool, Oct. 2nd, 1900.

RONALD Ross, D.P.H.

\section{BERI-BERI.}

To the Editors of THE Lancet.

SIRS,-Into the Provincial Hospital, Port Elizabeth, to which I was attached for many years, cases have been admitted from ships arrived from the East the diagnosis of which has been disputed. They have presented symptoms I think common to two diseases-" malaria," so called, and "beri-beri." Being health officer to the port as well as medical officer to the hospital some eight or 10 years ago I sent on shore several members of a crew who had been in an Eastern port. They were stated to have suffered from "fever" more or less for a considerable time; they presented, if I remember rightly, the usual appearance of feverstricken patients-anæmia, sallow skin, emaciation, and more or less cdema of the limbs, \&c.-a picture familiar to anyone who has lived in the East, Mauritius, or Madagascar. It so happened, I think, that the subject of beri-beri was being written and talked about at that time and it became a disputed point whether the men should be allowed to remain in or be removed to the lazaretto. Having on previous occasions admitted men in like condition without ill result following I pressed their being allowed to stay, which was done. No harm came from it, and after good nursing and rest they were allowed to go ont to be sent home by steamer on a certificate from me that no harm was to be anticipated. No deaths occurred. Had these been the subject of beri-beri the outcome of the affair, I imagine, would have been very different as regards the patients themselves. I had never seen a case of beri-beri, neither had any of the local medical men. All we knew of the malady was from books. Since then I learn that " beri-beri is an endemic form of " peripheral neuritis,' pathologically in the same category as diphtheria, alcoholic, and other forms of neuritis." ' In a late Port Elizabeth paper I learn that cases have occurred in Algoa Bry of a like nature, that the port officer advised their admission in to the Provincial Hospital, that the hospital authorities objected, and I believe the men were sent to a lazaretto.

To prevent any further friction in similar cases I should like to be informed in the pages of THE LANCET what is the differential diagnosis between cases of long-standing malaria and the disease called "beri-beri." Some of your readers who have had experience in the East might supply this information with great service to patients and hospital authorities. If there be a well-recognised "bacillus beri-beri," by sending a specimen of blood or local effusion to the nearest bacteriological institute-e.g., that of Graham's Town-this question might be decided at once and acted on. And what is the difference between the bacillus of "malaria" fever and that of beri-beri, if there be any? Is beri-beri considered infectious? It appears to be frequently fatal, hence the necessity of strict care in admitting such cases ; but how to prove their nature? From experience I know nothing of beri-beri, but from books only. The difference between extreme cases of malaria and beri-beri is difficult to decide and $I$ apprehend that the bacteriologisal examination of blood and tissues of these cases is the only scientific guide for action. The evidence of experiment and experience is much desired. I am, Sirs, yours faithfully,
Oct. 2nd, 1900.
F. ENSOR, M.R.O.S.

\section{"ANNUAL REPORT FOR 1899 ON BIRTHS, DEATHS, AND MARRIAGES IN IRELAND." \\ To the Editors of THE LANCET.}

SIRS,-In thanking you very heartily for the complimentary remarks you were pleased to make in your review in THE LANCET of Sept. 29th, 1900 (p. 963), of the Annual Report of the Registrar-General for Ireland for 1899 on my meteorological observations I wish to correct 